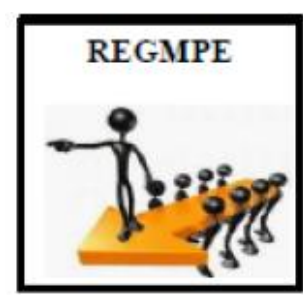

\title{
A INFLUÊNCIA DA HISTÓRIA DE VIDA DE UMA EMPREENDEDORA NA FORMAÇÃO DE UMA CONSULTORIA EMPRESARIAL
}

\section{THE INFLUENCE OF A FEMALE ENTREPRENEUR LIFE'S STORY IN THE FORMATION OF A BUSINESS CONSULTANCY}

\author{
Maria Rosangela Martins Brandão ${ }^{1}$ \\ Marcus Vinícius de Oliveira Brasil ${ }^{2}$ \\ Alandey Severo Leite da Silva ${ }^{3}$
}

\begin{abstract}
Resumo
O artigo é baseado na história de vida de uma empreendedora na área de consultoria empresarial, onde buscou-se discorrer sobre a relação existente entre a capacidade empreendedora e o desenvolvimento de uma empresa de consultoria empresarial de sucesso. O principal objetivo deste trabalho é analisar o perfil comportamental de uma empreendedora de sucesso. Logo, foram abordados os temas do empreendedorismo de uma forma geral, o empreendedorismo feminino e os tópicos de consultoria empresarial objetivando aprofundar o tema. Foi necessário identificar as características comportamentais da empreendedora, descrever suas experiências de vida e verificar o impacto daquelas na vida dela. A pesquisa foi realizada por meio de entrevista semiestruturada de cunho qualitativo. A entrevista e a análise dos dados foram divididas em duas dimensões: vida pessoal e vida profissional. Conclui-se que a empreendedora pesquisada possui as seguintes características empreendedoras: busca oportunidades e iniciativas, persistência, comprometimento, exigência de qualidade e eficiência, corre riscos calculados, estabelece metas, busca informações, planeja e monitora sistematicamente, persuasão e rede de contatos, independência e autoconfiança. Sugere-se ampliar e desenvolver outros casos de empreendedores locais e comparar com os dados desta pesquisa.
\end{abstract}

Palavras Chave: História de Vida. Empreendedora. Consultoria Empresarial.

\begin{abstract}
The article is based on the life story of a female entrepreneur in the business consulting area, it is intended to discuss the relationship between entrepreneurial capacity and the development of a successful business consulting company. The main objective of this work is to analyze the behavioral profile of a successful female entrepreneur. Soon, the themes of entrepreneurship in a general way, female entrepreneurship and the topics of business consultancy were addressed in order to deepen the theme. It was necessary to identify the entrepreneur's behavioral characteristics, describe her life experiences and verify the impact on her life. The research was carried out through a semi-structured qualitative interview. The interview and data analysis were divided into two dimensions: personal life and professional life. It is concluded that the researched entrepreneur has the following entrepreneurial characteristics: seeks opportunities and initiatives, persistence, commitment, demand for quality and efficiency, takes calculated risks, establishes goals, seeks information, systematically plans and monitors, persuasion and network of contacts,

1 Graduada em Administração pela Universidade Federal do Cariri-UFCA; rosangelavilinda2015@gmail.com;

2 Graduado, Mestre e Doutor em Administração; Graduado em Informática; Professor e Pesquisador da Universidade Federal do Cariri (UFCA); marcus.brasil@ufca.edu.br

3 Graduado, Mestre e Doutor em Administração e Ciências da Computação. Professor da Universidade Federal do Cariri (UFCA). alandey.severo@ufca.edu.br
\end{abstract}

Brandão, M.R.M., Brasil, M.V.O., Silva, A.S.L.; A Influência da História De Vida De Uma Empreendedora Na Formação De Uma Consultoria Empresarial. Revista de Empreendedorismo e Gestão de Micro e Pequenas Empresas V.5, No3, p.23-39, Set/Dez. 2020. Artigo recebido em 20/07/2020. Última versão recebida em 02/10/2020. Aprovado em 15/11/2020. 
A Influência da História De Vida De Uma Empreendedora Na Formação De Uma Consultoria Empresarial.

independence and self-confidence. It is suggested to expand and develop other cases of local entrepreneurs and to compare with the data of this research.

Keywords: Life Story. Female Entrepreneur. Business Consulting.

\section{INTRODUÇÃO}

O cenário brasileiro para empreendedores se mostra cada vez mais desafiador, dessa forma a busca de capacitação, informações sobre o mercado onde atua e diferenciais na sua atuação são pontos necessários para sobrevivência no ambiente de crise como o atual cenário brasileiro.

Segundo o Global Entrepreneurship Monitor, GEM (2017), o Brasil, em 2016, atingiu a segunda maior Taxa Total de Empreendedores de sua série histórica, o que contou com 36\% da população adulta envolvida com a atividade empreendedora. Depois de uma longa série de crescimento destes indicadores, a queda deles em 2016 está relacionada à crise da economia brasileira e/ou a um esgotamento natural do crescimento destes indicadores, após atingir o recorde no ano anterior.

Ainda segundo o GEM (2017), que é a principal instituição pesquisadora de empreendedorismo do mundo, as mulheres representam, em 2016, 51\% dos empreendedores que iniciam negócios, o que contribui para o aumento da autonomia financeira das mulheres. Além disso, a renda das mulheres tem ganhado cada vez mais relevância no orçamento familiar. Isso porque quatro em cada dez lares brasileiros são liderados por mulheres, conforme dados da Pesquisa Nacional por Amostra de Domicílios (PNAD, 2015). Dessas, $41 \%$ são donas de negócios próprios. Com esse cenário o empreendedor procura cada vez mais alternativas para driblar as controvérsias do mundo empreendedor. Para isso uma das alternativas é a busca por assessoria e capacitação empresarial. Aparece aí a figura do consultor.

De acordo com a pesquisa realizada pela GEM em 2015, no Brasil, o percentual de empreendedores na faixa etária de 18 a 64 anos foi de 39,3\%. Desses entrevistados 50\% afirmam possuir conhecimentos, habilidades e experiências necessárias para abrir um negócio, sendo que para $60,9 \%$ deles a possibilidade de fracasso não seria empecilho para empreender. Ainda segundo a pesquisa, ser dono do próprio negócio aparece em terceiro lugar na lista de desejos e expectativas dos brasileiros adultos, com 31,4\%. Na Região Nordeste do país, o SEBRAE é o órgão de apoio mais procurado por aqueles que desejam empreender e acham necessário buscar algum apoio para tal ação (GEM, 2015).

Dessa forma percebe-se a importância do papel do empreendedorismo no desenvolvimento econômico e social de um país. Para esse trabalho focou-se no relato da história de vida de uma jovem empreendedora proprietária de uma empresa de consultoria na região do Cariri, que obteve êxito nos negócios, por abordar um tema onde ainda há novos elementos de reflexão e que enriquecem o estudo do empreendedor local. Diante disso, surge a seguinte problemática: Quais características comportamentais são necessárias para o sucesso de mulheres empreendedoras?

Assim o objetivo geral desse estudo é analisar o perfil comportamental de uma empreendedora de sucesso. Para contemplar este objetivo, o estudo tem os seguintes objetivos específicos: perceber as características comportamentais da empreendedora; descrever experiências de vida da empreendedora; entender como o processo empreendedor bemsucedido é alcançado na vida de uma empresária de sucesso.

\section{MARCO TEÓRICO}


A Influência da História De Vida De Uma Empreendedora Na Formação De Uma Consultoria Empresarial.

\subsection{Empreendedorismo}

O termo empreendedorismo possui diversos significados na prática, alguns deles divergentes entre si, porém uma definição introduzida por Baron e Shane (2007) sugere que o empreendedorismo é uma área de negócios, buscando entender como surgem às oportunidades para criar algo novo (novos produtos ou serviços, novos mercados, novos processos de produção ou matérias-primas, novas formas de organizar as tecnologias existentes); como são descobertas ou criadas por indivíduos específicos, ou seja, identificar oportunidades, que tenha potencial valioso no intuito de poder ser explorada em termos práticos como um negócio (ou seja, uma oportunidade que possa produzir lucros sustentáveis) e identificar as atividades envolvidas na exploração ou no desenvolvimento real dessa oportunidade.

A atividade empreendedora é considerada um fenômeno global, dada a sua força e crescimento, nas relações internacionais e na formação profissional. O Brasil é apontado como um dos países mais criativos do mundo e onde mais se desenvolvem empreendedores (MATIAS, 2016). De acordo com Chiavenato (2014) os empreendedores são heróis populares no mundo dos negócios, uma vez que fornecem empregos, introduzem inovação e incentivam o crescimento econômico. O autor ainda expõe que os empreendedores não são apenas provedores de mercadorias ou de serviços, mas fontes de energia que assumem riscos em uma economia em transformação e crescimento. Segundo Dornelas (2008) e Matias (2016) os empreendedores são pessoas que começam algo novo e assumem diversos riscos. Estes indicam que as distinções fundamentais desse termo estão na iniciativa e na capacidade de utilizar os recursos disponíveis de maneira criativa.

O conceito de empreendedorismo tem sido muito difundido no Brasil nos últimos anos, intensificando-se no final da década de 1990. Na primeira década do século XXI, o termo se popularizou com a preocupação do governo e das entidades de classe em criarem micro e pequenas empresas duradouras e diminuir as altas taxas de mortalidade dos empreendimentos. Segundo Dornelas (2008) o empreendedorismo no Brasil inicia-se basicamente do aumento dos índices de desemprego nas grandes cidades, onde se encontra maior agrupamento de empresas, assim na busca por novas alternativas de gerar renda, estes desempregados iniciam novos negócios com as economias pessoais vindas do último trabalho e com, em muitos casos, nenhuma ou pouca experiência na atividade. Quando estes percebem, se tornam patrões, e já não mais funcionários.

De acordo com o Serviço de Apoio às Micro e Pequenas Empresas - SEBRAE a taxa de empreendedorismo no Brasil em 2015 chegou a 39.3\%, assim cerca de 52 milhões de brasileiros com idade entre 18 e 64 anos estavam envolvidos na criação ou manutenção de algum negócio na condição de empreendedor em estágio inicial ou estabelecido (GEM, 2015). No panorama apresentado pela GEM (2015) a criatividade e a resiliência são citadas como características dos brasileiros que favorecem o empreendedorismo.

Nesse universo o empreendedorismo feminino vem apresentando um panorama com um modelo de gestão diferenciado (MATIAS, 2016). Para Villas Boas (2010) o comportamento empreendedor do público masculino e feminino apresenta importantes diferenças.

\subsection{Comportamento Empreendedor}

Bueno, Leite e Pilatti (2004) afirmam que os empreendedores possuem características que os diferenciam e buscam aperfeiçoá-las, é aquele indivíduo que quer aprender e buscar o autoconhecimento e se atualiza dentro do meio em que atua. Os autores ainda afirmam que algumas necessidades acabam influenciando o comportamento e a vida do empreendedor, e que 
A Influência da História De Vida De Uma Empreendedora Na Formação De Uma Consultoria Empresarial.

algumas qualidades e valores acompanham um empreendedor durante toda a vida, enquanto outros são adquiridos com experiência.

David C. McClelland realizou, em 1972, uma pesquisa de nível mundial para detectar as características comuns em empreendedores bem-sucedidos. Ele elenca dez principais características comportamentais empreendedoras e as reúne em três principais grupos de necessidade, estudadas pelo autor, são elas: busca de oportunidades e iniciativa; correr riscos calculados; exigência de qualidade e eficiência; persistência; comprometimento (pertencentes ao conjunto de realização); Busca de informações; estabelecimento de metas; planejamento; monitoramento sistemático (pertencentes ao conjunto de planejamento); persuasão e rede de contatos (pertencente ao conjunto de poder), (SOUZA; FRACASSO, 2008).

Segundo Teixeira et al (2011) um empreendedor de sucesso possui características extras, que vão além dos atributos pessoais que somados a características externas como as sociológicas e ambientais, permitem o desenvolvimento e até mesmo a criação de um novo negócio. No quadro abaixo são apresentadas as principais características empreendedoras segundo vários autores:

\begin{tabular}{|c|c|c|c|c|c|}
\hline DORNELAS & DOLABELA & McCLELLAND & TIMONNS & BHIDÉ & FILION \\
\hline $\begin{array}{l}\text {-Visionário } \\
\text { - Sabe tomar } \\
\text { decisões. } \\
\text { - Indivíduo } \\
\text { que faz a } \\
\text { diferença. } \\
\text { - Sabe } \\
\text { explorar ao } \\
\text { máximo a } \\
\text { oportunidade. } \\
\text { - } \\
\text { Determinado } \\
\text { e dinâmico. } \\
\text { - Dedicado. } \\
\text { - Otimista e } \\
\text { apaixonado } \\
\text { pelo que faz. } \\
\text { - Independente } \\
\text { e constrói o } \\
\text { próprio } \\
\text { destino. } \\
\text { Lider. }\end{array}$ & $\begin{array}{l}\text { - Possui um } \\
\text { "modelo", uma } \\
\text { pessoa que o } \\
\text { influencia. } \\
\text { - Iniciativa, } \\
\text { autonomia e } \\
\text { otimismo, } \\
\text { autoconfiança, } \\
\text { necessidade de } \\
\text { realização. } \\
\text { - Trabalha sozinho. } \\
\text {-Perseverança e } \\
\text { tenacidade. } \\
\text { - Aprende com os } \\
\text { erros. } \\
\text { - Grande energia, é } \\
\text { incansável. } \\
\text { - Fixa metas e as } \\
\text { alcança. } \\
\text { - Forte intuição. } \\
\text { Comprometimento }\end{array}$ & $\begin{array}{l}\text { - Busca de } \\
\text { oportunidades e } \\
\text { iniciativa. } \\
\text { - Persistencia. } \\
\text { - Exigência de } \\
\text { qualidade e } \\
\text { eficiência. } \\
\text { - Assume riscos } \\
\text { calculados. } \\
\text { - Determina metas. } \\
\text { - Busca } \\
\text { informações. } \\
\text { - Planejamento e } \\
\text { monitoramento } \\
\text { sistemático. } \\
\text { - Persuasão e rede } \\
\text { de contatos. } \\
\text { - Independência e } \\
\text { autoconfiança. } \\
\text { - Comprometimento }\end{array}$ & $\begin{array}{l}\text { - Comprometimento, } \\
\text { determinação e } \\
\text { perseverança. } \\
\text { - Busca } \\
\text { autorrealização, } \\
\text { crescimento, com } \\
\text { metas desafiadoras. } \\
\text { - Senso de } \\
\text { oportunidade e } \\
\text { orientação para } \\
\text { metas. } \\
\text { - Iniciativa pelo } \\
\text { senso de } \\
\text { responsabilidade } \\
\text { social. } \\
\text { - Persistencia e } \\
\text { determinaçãona } \\
\text { resolução de } \\
\text { problemas. } \\
\text { - Enfrenta situações } \\
\text { adversas com } \\
\text { otimismo, humore } \\
\text { perspectiva. } \\
\text { - Busca feedback do } \\
\text { desempenho e } \\
\text { aprende com os } \\
\text { erros. }\end{array}$ & $\begin{array}{l}\text { - "Não existe } \\
\text { perfil ideal. Os } \\
\text { empreendedores } \\
\text { podem ser } \\
\text { gregários ou } \\
\text { taciturnos, } \\
\text { analiticos ou } \\
\text { intuitivos, } \\
\text { cautelosos ou } \\
\text { ousados". } \\
\text { - Não se pode } \\
\text { definir um } \\
\text { modelo único } \\
\text { de perfil } \\
\text { empreendedor. }\end{array}$ & $\begin{array}{l}\text { - Pessoa } \\
\text { criativa. } \\
\text { - Marcada } \\
\text { pela } \\
\text { capacidade } \\
\text { de } \\
\text { estabelecer } \\
\text { e atingir } \\
\text { objetivos. } \\
\text { - } \\
\text { Visionário. }\end{array}$ \\
\hline
\end{tabular}

Figura 1- Resumo das principais características do empreendedor segundo diferentes autores.

Fonte: Teixeira et al., (2011)

Inúmeros autores tentam traçar o perfil ideal do empreendedor, acreditando que suas motivações de realização e suas características comportamentais são responsáveis pelo processo e determinantes nele, todavia, não existe um padrão nem estudos comprovados cientificamente sobre as características empreendedoras, as potencialidades de empreender desafiam as diversidades de percepções para ampliação do aprendizado (TEIXEIRA, et al., 2011). 
A Influência da História De Vida De Uma Empreendedora Na Formação De Uma Consultoria Empresarial.

\subsection{Empreendedorismo Feminino}

As mulheres possuem uma forma de trabalho diferenciada dos homens, com sua excelente capacidade de persuasão e grande preocupação com clientes e fornecedores, elas contribuem ainda mais para o progresso da empresa. Dessa forma, estão cada vez mais conquistando o seu espaço no mundo dos negócios, o que mostra perante elas, uma capacidade e força empreendedora ao longo dos anos. De acordo com as estatísticas firmadas por uma pesquisa fomentada pelo SEBRAE (Global Entrepreneurship Monitor), mostram que 49\% dos novos empreendimentos que estão surgindo são comandados por pessoas do sexo feminino (GEM, 2015).

Buscar por mais qualificações e acesso à informação tem sido os alvos fundamentais de investimento das mulheres. Estas buscam ser mais profissionais, isso se justifica pelo índice de escolaridade dos donos de novos negócios, onde $49 \%$ (onde as mulheres são a maioria) têm pelo menos o $2^{\circ}$ grau completo, já nos negócios estabelecidos, com mais de três anos em atividade, onde os homens são a maioria, esse índice é de 41\% (GEM, 2015).

Estudos atuais demonstram que as mulheres estão criando novas empresas por diferentes motivos: sejam apenas pelo fato da necessidade de sobrevivência, como também, pela percepção de oportunidade de mercado, dificuldades em ascender na carreira profissional em outras empresas ou até mesmo pelo desejo de realização e independência (TAKAHASHI, et al., 2011).

Pesquisas mostram que o perfil da mulher empreendedora, atribuído as suas principais características gerenciais são primordiais para a tomada de decisão e apresentam aspectos de liderança e postura formidáveis para o mundo empreendedor. $\mathrm{O}$ sexo feminino tende a realçar qualidade mais do que o sexo masculino, o que revela ser uma postura favorável ao envolvimento familiar na organização e assim, propõe a empregar mais mulheres do que homens. A combinação de características masculinas (iniciativa, coragem e determinação) com características femininas (sensibilidade, intuição e cooperação) define um estilo próprio de gerências por parte das empreendedoras. Tal estilo, aliado à intensa dedicação ao trabalho por parte das mulheres empreendedoras, contribui para o aumento das taxas de sobrevivência de empresas geridas por mulheres (MACHADO, 1999, apud TAKAHASHI, et al. 2011).

Entre muitas características das empreendedoras destaca-se a sensibilidade, maior empatia, comprometimento e vontade de ajudar, além de incentivar a participação e o compartilhamento de informações entre os funcionários, tornando estas, com atributos positivos para o sucesso empreendedor. A autora ainda reforça que atualmente as mulheres têm assumido características que antigamente eram atribuídos aos homens, como a competitividade, liderança, ambição, capacidade de assumir riscos, aceitação de mudanças, pensamento analítico e objetivo, assim tornando estas capazes de enfrentarem o mundo dos negócios com o mesmo nível de relevância do que os empreendedores masculinos (MATIAS, 2016).

\subsection{Consultoria Empresarial}

\subsubsection{Histórico da Consultoria}

A consultoria no seu sentido mais amplo pode ser considerada uma das atividades mais antigas do mundo, sendo considerada a origem da palavra, consultare, oriunda do latim, que tem como significado "dar ou receber conselhos, aconselhar e também ser aconselhado". Na antiguidade, a atividade era baseada na observação sistemática e inteligente a partir dos fenômenos naturais que eram desenvolvidas pelos primitivos consultores a partir do seu saber (JACINTHO, 2004).

Para Conceição (2015) a consultoria existe desde então, porém teve maior concentração no 
A Influência da História De Vida De Uma Empreendedora Na Formação De Uma Consultoria Empresarial.

período do século XIX e XX, sendo identificadas as primeiras consultorias organizacionais na Inglaterra. Onde segundo Alves, Dias e Monsores (2015) a revolução industrial proporcionou o aumento da demanda por profissionais qualificados, ocasionando o surgimento da primeira empresa de consultoria. Nos EUA o ramo de consultorias se consolidou após a Segunda Guerra Mundial, onde o governo norte-americano viu-se obrigado a contratar os serviços de consultoria para reorganizar o setor militar. Esta ação influenciou o resto do mundo.

Nas décadas de 40 e 50 os EUA e a Europa Ocidental fizeram importantes avanços na sistematização do trabalho de consultoria, abandonando as experiências empíricas e incorporando a vinculação eminentemente técnica e científica fundamentada em teorias, sem deixar de lado o foco nas soluções práticas (CONCEIÇÃO, 2015).

Donadone, et al. (2012) apontam os EUA como o maior líder no setor de consultoria, já o Brasil é um dos países que mais cresce nesse segmento. Logo, percebe-se que por via do avanço da nova economia, e por conta da readequação das organizações, aconselha-se para as pequenas empresas um profissional qualificado capaz de auxiliar as mesmas no seu desenvolvimento (ALVES; DIAS; MONSORES, 2015).

\subsubsection{Conceitos e Características da Consultoria}

Jacintho (2004) define a consultoria sendo a ação em que um cliente fornece ou solicita opiniões, estudos e análises a um especialista contratado para que o mesmo auxilie através de apoio e orientações no seu trabalho administrativo. Parreira (1997) propõe uma categorização na qual evidencia alguns aspectos da consultoria: sendo uma troca; um serviço especializado; não sendo um serviço caro; sendo um serviço ético; e um serviço de orientação.

A consultoria é o principal meio de administrar as rápidas transformações no contexto organizacional mundial e a necessidade de conhecimento especializado (CONCEIÇÃO, 2015). Para estar habilitado a ajudar, o consultor deve desempenhar habilidades e conhecimentos necessários para a empresa do cliente, ao passo que a empresa deverá estar aberta a colaboração para que as contribuições sejam geradas através de mudanças (JACINTHO, 2004).

Dentro deste aspecto, Oliveira (2001) define consultoria empresarial sendo um processo interativo de um agente de mudança externo à empresa, capaz de assumir responsabilidade em auxiliar os executivos e profissionais da empresa contratante de tais serviços nas tomadas de decisões, não tendo, entretanto, o controle direto da situação.

Jacintho (2004) levanta a seguinte questão: o trabalho de consultoria é um trabalho de diagnóstico, aconselhamento e orientação para a implantação de soluções sem, no entanto, ocorrer um envolvimento na execução, pois a partir do momento que o consultor passa a ter controle direto da situação ela deixa de ser consultor e passa a ser um executivo da empresa cliente.

Entretanto, Oliveira (2001) afirma que mesmo não tendo o controle direto da situação, o consultor não deve colocar-se como quem não tem responsabilidade pelos resultados da implementação do projeto que idealizou, estruturou e desenvolveu.

Jacintho (2004) assegura que os consultores são conselheiros e sua responsabilidade cabe apenas à qualidade e integridade dos conselhos que disseminam, e cabe aos clientes a responsabilidade referente à aceitação destes conselhos. $\mathrm{O}$ mesmo autor ainda exalta que não basta que o conselho certo seja dado, mas que seja dado de forma adequada e no momento certo, residindo aí, a habilidade fundamental do consultor.

A Consultoria surgiu de maneira informal de pessoas tentando ajudar, dar conselhos a outras. Porém com o passar do tempo, a consultoria passou a ser considerada de forma sistematizada. Com o surgimento da consultoria de forma sistematizada, as pequenas empresas vêm nela uma ferramenta onde pode auxiliar as mesmas na sua gestão (ALVES; DIAS; 
A Influência da História De Vida De Uma Empreendedora Na Formação De Uma Consultoria Empresarial.

MONSORES, 2015).

\subsubsection{Tipos de consultoria}

Jacintho (2004) expõe diversas abordagens para os tipos de consultoria, porém visando dar um enfoque geral aos tipos de consultoria e explanar as atividades gerais,Schein (1972) apud Jacintho (2004), estabelece três tipos básicos de consultoria:

a) Modelo de compra de serviço especializado:onde o consultor é um especialista e vende seu serviço especializado;

b) Modelo médico-paciente: onde o consultor é convidado para realizar um diagnóstico, identificar os problemas e indicar qual o tratamento adequado para melhorar os resultados da empresa-cliente;

c) Modelo da Consultoria de Procedimentos:aqui o enfoque é na percepção do próprio cliente para entender e agir sobre os fatores inter-relacionados que ocorrem no ambiente. Neste tipo de consultoria oconsultor e o cliente elaboram um diagnóstico em conjunto.

Quanto à natureza do serviço Kurb (1986) apud Jacintho (2004) descrevem os tipos de consultoria sendo:

a) Diagnóstico empresarial: o consultor pesquisa os recursos da organização, seus resultados, as políticas e padrões de administração, para definir suas forças e fraquezas e identificar problemas-chave que impactam no desempenho do negócio;

b) Pesquisas e estudos especiais: o consultor atua focado em assunto de importância para a organização cliente, sendo que ao encerrar o trabalho, submete um relatório final, discutindo-o com o cliente;

c) Elaboração de soluções para problemas específicos: o cliente necessita mais que um diagnóstico, necessitando de soluções para problemas específicos. O trabalho estará concluído quando o cliente entender que recebeu uma solução adequada para seu problema;

d) Assistência na implementação: após o diagnóstico e a elaboração da solução, a empresa-cliente pode precisar de apoio na implantação. Pode envolver seleção e treinamento de pessoal, ajudando o administrador a mobilizar as pessoas em direção aos resultados esperados;

e) Aconselhamento: o consultor atua no sentido estrito da palavra: respondendo a perguntas quando solicitando. Deve cuidar, no entanto, para não passar para o papel de árbitro. A decisão caberá ao cliente.

Uma questão a ser considerada é que a postura de não executar é muitas vezes confundida com não acompanhar a execução. Este procedimento pode gerar grandes críticas dos clientes ao processo de consultoria, pois o sentimento que pode ficar é de que o consultor entra na empresa, questiona tudo e depois apresenta uma proposta que não acompanha para ver se deu certo (CONCEIÇÃO, 2015).

\section{MÉTODO}

O referido estudo se materializa enquanto uma pesquisa qualitativa, sendo ao mesmo tempo bibliográfica e documental, onde Lakatos e Marconi (2010) dizem que a pesquisa bibliográfica, abrange toda bibliografia já tornada pública em relação ao tema de estudo, que variam desde publicações como: revistas, livros, pesquisas, monografias e outros. O estudo conta 
A Influência da História De Vida De Uma Empreendedora Na Formação De Uma Consultoria Empresarial.

ainda com um arcabouço documental, que possibilita a compreensão referente ao assunto abordado, possibilitando que o pesquisador se aproxime ainda mais do objetivo, partindo de uma ampla análise dos conteúdos baseando-se em documentos.

A pesquisa qualitativa, não tem como principal finalidade encontrar dados estatísticos ou que possam ser demonstrados através de gráficos, tabelas ou números, mas pode e deve ser entendido como um estudo que demonstra as particularidades e compreensões sobre uma realidade (MINAYO, 2007).Trata-se ainda de uma pesquisa, onde se utiliza o método do levantamento bibliográfico a fim de aprimorar a compreensão do pesquisador sobre o tema e proporcionar pontos de discussão para a segunda etapa, a coleta de dados, onde buscou-se compreender e descrever a influência da história de vida de uma empreendedora na sua empresa de consultoria.

O sujeito da pesquisa é uma empreendedora do ramo de consultoria empresarial, com empresa estabelecida no município de Juazeiro do Norte, estado do Ceará. A intencionalidade deu-se pelo seu destaque na região caririense, além da disponibilidade e receptividade da empreendedora em contribuir para a pesquisa.

O instrumento de coleta de dados foi à entrevista semiestruturada, apresentada no apêndice desse estudo. Sua aplicação deu-se da forma face a face sendo o entrevistador o próprio pesquisador. Para Triviños (1997, p. 146)“a entrevista, ao mesmo tempo em que valoriza o investigador, oferece todas as perspectivas possíveis para que o informante alcance a liberdade e a espontaneidade necessárias, enriquecendo a investigação".

No total foram feitas três entrevistas com a empreendedora, onde essas entrevistas foram gravadas e transcritas para construir a história de vida. As entrevistas foram realizadas nos dias 03 de abril, 05 de junho e 7 de junho de 2017.

\section{RESULTADOS E DISCUSSÃO}

Com o intuito de responder quais características comportamentais são necessárias para o sucesso de mulheres empreendedoras, adotou-se como objetivo geral desta pesquisa analisar o perfil comportamental de uma empreendedora de sucesso. Para tal, os objetivos específicos do trabalho foram: perceber as características comportamentais da empreendedora; descrever experiências de vida da empreendedora; entender como o processo empreendedor bem-sucedido é alcançado na vida de uma empresária de sucesso.

Schuly aborda que, na visão de McClelland (1972), a motivação para a realização mostrase como um traço inconsciente que é efeito principalmente das experiências vividas na infância, da forma como as crianças são tratadas pelos pais, e ainda completa que as primeiras experiências possuem um papel amplo e perene nas futuras situações (SCHUHLY, 1995).

Diante disso, a pesquisa abordou dados da vida pessoal, onde foram abordadas situações da infância, adolescência e início da vida adulta; e dados profissionais, porém, em muitas vezes os dois se relacionam.

\subsection{Análise da entrevista}

Schuhly (1995), diz que existe uma correlação entre o rendimento e o ambiente familiar. Diante disso e do que foi exposto por McClelland, no início dessa sessão, será traçado um paralelo da conjuntura entre o processo de crescimento da empreendedora, sua família e na construção de sua personalidade, marcada pelo empreendedorismo.

Consultora de negócios, carreira desenvolvida na região do Cariri, casada, 33 anos, mãe, mulher visionária, a empreendedora em questão desde criança teve influência empreendedora que 
A Influência da História De Vida De Uma Empreendedora Na Formação De Uma Consultoria Empresarial.

foi determinante para direcioná-la a um futuro profissional brilhante nos negócios.

Nascida no dia 6 de agosto de 1983 em São Bernardo do Campo, município do estado de São Paulo, a empresária empreendedora aprendeu desde cedo o significado das palavras garra e superação. Com o falecimento do pai, vítima de um infarto, ela com apenas 4 anos, acompanhada de sua mãe, mudaram-se para a capital do Ceará, Fortaleza, já que sua mãe era natural da cidade cearense.Com uma vida regrada, por limitações financeiras, e sem ter com quem deixar a filha, a mãe sempre a levava para acompanhá-la em sua profissão de sacoleira, o que contribuiu para o desenvolvimento do lado comunicativo da empreendedora "ela passava o dia vendendo roupas e eu ouvindo e aprendendo a falar e aprendendo a me relacionar", relata a empresária. A empreendedora passou por infância difícil e cheia de necessidades, onde evidencia como a infância impactou na sua personalidade atual, ratificando a abordagem de Schuhly (1995).

Mesmo atuando como sacoleira e costureira, sua mãe muitas vezes necessitou da ajuda financeira de familiares para poder pagar os estudos da filha e sempre a incentivando a estudar: "minha mãe me motivava a ser muito estudiosa para ganhar bolsa e para a gente puder mudar de vida", diz a empreendedora. E logo complementa: "eu era das turmas especiais do colégio Farias Brito eu tinha uma bolsa de $50 \%$ e também era atleta, eu jogava Vôlei, era da seleção que ratificava minha bolsa" (ENTREVISTA, abril, 2017).

Autores como Filion (1999) e Dolabela (1999) destacam que quando a pessoa tem um modelo familiar ou o ambiente em que vive propício a empreender, há uma maior probabilidade dela vir a se tornar empreendedora.

Estimulada pela mãe a seguir a carreira de Medicina ou de Direito, a consultora acabou traçando seu próprio futuro e escolheu a Publicidade como sua futura profíssão, "eu fiz Publicidade porque eu achava que eu gostava da área de comunicação e de lidar com clientes, com a ideia da criatividade de lidar com o consumidor. Eu sentia afinidade por esses temas", conta a consultora. (ENTREVISTA, abril, 2017).

No primeiro semestre ela já fazia metas e traçava planos de como obter uma renda extra para ajudar a mãe com as despesas "assim que eu entrei na faculdade, eu trabalhava em eventos, eu fazia panfletagem, eu servia refrigerantes nos supermercados", relata a empreendedora. Ela ainda afirma que tais experiências foram primordiais para seu crescimento profissional "hoje eu entendo de merchandising, de estratégia promocional, porque eu vivenciei aquilo na prática" (ENTREVISTA, abril, 2017).

Percebe-se aqui a eminência de algumas características presentes na bibliografia estudada que foram desenvolvidas desde a infância da empreendedora, são elas: independência e autoconfiança; persuasão e redes de contatos; busca de informações; persistência, estabelecimento de metas e busca de oportunidades e iniciativa. Características estas que ainda estarão em processo de desenvolvimento diante de experiências vividas também na vida adulta e profissional da mesma.

Aos 21 anos ela se tornou consultora, ainda muito jovem, um pouco antes de terminar sua graduação, conseguiu um emprego na multinacional Petrobrás. Mesmo se considerando jovem, a consultora de origem humilde não se amedrontava diante do desconhecido, para ela aquilo servia de gatilho impulsionador para buscar sempre dar seu melhor "Eu ia sem ter medo, dava os treinamentos para várias pessoas e não me desencorajava por ser jovem, por não conhecer as coisas", conta ela. (ENTREVISTA, abril, 2017).

Conforme os autores expostos no quadro I, a heterogeneidade perceptiva amplia o aprendizado, desafia o intelecto, aguça o espírito indagador e o poder de observação. Podem ainda estar relacionados, a autorrealização em empreender e o orgulho de transformar um sonho em uma atividade que permita a obtenção de uma maior independência.

A busca pelo conhecimento somado a experiência adquirida na empresa a incentivou a 
A Influência da História De Vida De Uma Empreendedora Na Formação De Uma Consultoria Empresarial.

ousar cada vez mais e a consultora focou nos estudos e passou no mestrado em Administração. Em 2007, ela começou a exercer a profissão de professora na Universidade Estadual do Ceará. E nesse mesmo ano ela se casou com um caririense, formado em direito e hoje Juiz. Essa união rendeu mais uma mudança, como seu esposo passou no concurso de juiz, em 2009 o destino escolhido foi Juazeiro do Norte-CE.

De início, a empreendedora recolocou-se no mercado de trabalho como professora, sendo que ela já exercia essa profissão na capital cearense, no Cariri ela começou a lecionar na Faculdade de Juazeiro do Norte, Faculdade Paraíso e Faculdade Leão Sampaio. Em 2010, a então consultora e professora universitária subiu mais um degrau em sua vida acadêmica e torna-se doutoranda em Administração pela Universidade de Fortaleza. A atualização constante para uma maior leitura e planejamento de atuação no mercado deve ser buscada pelo empreendedor, isso é um ponto abordado nas características, busca de informações e busca de oportunidades e iniciativa, trazidas por McClelland (1972) que são percebidas nas palavras da consultora.

Em seu currículo conta ainda com o título de Professora de Pós-Graduação, Coaching com mais de quatro certificações internacionais e autora de três livros. O primeiro aborda a fusão do Bradesco com o BEC (Banco do Estado do Ceará), o processo de comunicação aos funcionários e de mudança. O segundo foi sobre o empreendedorismo coletivo e o terceiro lançado em 2017, em conjunto com a CDL (Câmara de Dirigentes Lojistas), traz a biografia de 29 empresários do Cariri que inspiram. Além de mais um em andamento, esse vai contar a trajetória de vida de muitas mulheres empreendedoras do Cariri.

Apesar de não garantirem o sucesso do negócio, a ausência das características dos empreendedores de sucesso, poderão ocasionar dificuldades em alcançar o sucesso empresarial, visto que alguns traços de personalidade são cruciais para quem pretende se aventurar no mundo dos negócios. Para chegar ao perfil ideal e ser bem-sucedido, o empreendedor precisa conhecer suas características empreendedoras, detectando o que pode ser aperfeiçoado e desenvolvendo as potencialidades (GREATTI, 2003).

Diante disso, salienta-se quais características estavam presentes no processo de criação e desenvolvimento do negócio da consultoria, onde com um perfil profissional aperfeiçoado, a consultora decidiu se aventurar no universo empreendedor. Com a mente de quem enxerga além, acreditando no potencial da região caririense e em sua capacidade transformadora de fazer a diferença. Em 2012, ela abre a sua empresa de consultoria.

Localizada no município de Juazeiro do Norte, atende empresas de pequeno, médio e grande porte da Região do Cariri. Contando com cinco funcionários, a empresa oferece ferramentas de gestão de mercado, presta consultoria e treinamentos empresariais nas áreas de gestão de equipes por resultados e gestão financeira.

Em apenas quatro anos no mercado a empresa, já treinou mais de oito mil pessoas e já atendeu mais de 150 empresas, dentre elas a Cajuína São Geraldo e o Grupo J. Gondim.

A organização tornou-se a consultoria mais premiada no Cariri, no ano de 2017 o seu faturamento teve um crescimento de $40 \%$ e seu quadro de funcionários aumentou em $25 \%$, além de abrirem mais uma área na empresa, a de Coaching.

Mas o sucesso não surgiu de uma hora para outra, como conta ela: "o que eu tive de desafio quando eu cheguei aqui, foi porque as pessoas não conheciam, então eu bati em várias portas, levava muito chá de cadeira, esperava para ser recebida, a pessoa recebia, às vezes não acreditava". Nas palavras da consultora é percebido a persistência e comprometimento dedicado por ela no processo de criação do seu negócio e em seguida, a consultora complementa que "e com o passar do tempo, graças a Deus o nome foi criando força, a gente foi ganhando repercussão, muita indicação e hoje as pessoas mais vêm até nós, do que nós vamos até elas". A entrevistada destaca a sua coragem como um comportamento empreendedor de maior grau que se 

Empresarial.

sobressai nela. Admitindo que a base sólida na qual sua empresa foi fundada, é fruto de cálculos e riscos controlados, sempre buscando arriscar em ideias que motive extrair o seu melhor (ENTREVISTA, abril, 2017). Dornelas (2001) destaca que empreendedores são pessoas independentes que constroem o próprio destino. São dotados de autonomia e motivados para atuar em seus próprios negócios com êxito.

A sua pretensão com a consultoria era a de se tornar referência na região do Cariri em sua área de atuação, e buscar sua realização profissional, "a gente atende 32 empresas ao mesmo tempo, acredito que nós somos uma das maiores consultorias da região. Tem o nome já forte. Atendemos grandes clientes", afirma ela. Alega ainda, que é um privilégio poder fazer parte da evolução da região, visto que tinham vários pontos a serem melhorados nos profissionais caririenses: "a gente viu que o nível de atendimento ao cliente era baixo, o nível de profissionalização das empresas era baixo, e poder contribuir com a mudança do Cariri era o nosso maior objetivo", afirma a empreendedora (ENTREVISTA ,abril, 2017).

A consultoria é focada para potencializar os resultados das empresas, intencionando manter a perenidade no mercado e favorecendo a geração de empregos. Visando aumentar a satisfação dos clientes em relação aos seus serviços e atendimento, enxergando uma potencialidade turística para região, e aquecer a economia do Cariri.

Os empreendedores prezam por alcançar o nível mais alto de excelência em seus trabalhos. Por tanto, exercem suas atividades com dedicação e empenho, agindo eficientemente de forma rápida e com redução de custos, assegurando que o trabalho seja finalizado a tempo. Assim, o resultado é satisfatório e, muitas vezes, ultrapassam os padrões de qualidade previamente combinados (GREATTI; SENHORINI, 2000).

A empreendedora é bem taxativa ao referenciar a credibilidade da consultoria como ponto forte "a gente tem um bom respeito da mídia, hoje mesmo a TV Verdes Mares chamou a gente para poder dar entrevista, a globo geralmente seleciona quem ela chama". A consultora conta ainda com um programa na rádio todas as segundas-feiras e tem um bom nível de relacionamento com a TV Verdes Vale, que faz questão de ter a participação dela em um dos seus programas (ENTREVISTA, abril,2017).

Uma das características do empreendedor é a competência de identificar e aproveitar uma oportunidade, tornando-a um negócio lucrativo e de sucesso. A oportunidade é abordada como obra do procedimento de observação a realidade de um exercício que só será retornável se praticado constantemente (GUEIROS, 2004). Lopes (2007) afirma que essa característica se refere à competência de se antecipar aos fatos e criar oportunidades de negócios.

A empresa estudada conta com um canal no Youtube com a finalidade de aproximar cada vez mais os residentes da região cariri à consultoria, levar conhecimento aos que buscam capacitação. E o canal tem trazido bons resultados, "geralmente as pessoas perguntavam quando a gente ia fazer palestras, eu sentia uma necessidade de estar me comunicando com esse público e também os colaboradores das empresas que atendemos" conta ela. "Os diretores podem acessar, se capacitar, e, além disso, é uma forma da gente explorar alguns casos de sucesso da nossa região", complementa (ENTREVISTA, junho, 2017).

Em relação aos pontos fracos da empresa, a consultora alega que o crescimento da consultoria não é paralelo a sua demanda, devido à falta de profissionais qualificados para tratar de determinado problema, e esse fator acaba causando um atraso no atendimento ao cliente.

Fomentado pelos estudos de (TAKAHASHI, et al., 2011), que mostram as mulheres como criadoras de empresas por diferentes motivos, a consultora apresenta que até no desenvolvimento do símbolo da sua empresa pensou no empoderamento feminino diante do mercado de trabalho, onde afirma que o símbolo que carrega a marca da empresa é a rainha, uma peça de xadrez que segundo ela, é a peça que tem maior mobilidade e conceitua a organização como uma 

Empresarial.

oportunidade de ir além do que se pode alcançar, uma ideia de poder ganhar mais amplitude no mercado competidor. Além de relacionar ao seu papel de mulher e diretora da empresa.

Ela também carrega consigo a ideologia de empoderar a mulher no mercado de trabalho. Em março de 2017, ela palestrou em um auditório lotado com mais de 450 mulheres, discutindo aspectos que atingem a mulher moderna. O sucesso foi tanto que já foi programada uma nova edição em 2018.

A consultora destaca que o papel da mulher no mercado de trabalho desmistificou muito durante os anos, e que os mitos em relação à falta de competência e capacidade para exercer determinados cargos e profissões foram enfraquecidos. Segundo ela "hoje a mulher atua em diversos segmentos e com destaque, então ela já provou que tem competência para atuar em qualquer área e assumir qualquer cargo de liderança". Em seguida completa dizendo: "no Cariri eu acho que a gente também teve várias conquistas, tem muitas empresárias bem-sucedidas, gerentes, diretoras de empresas. O que continua ainda é a diferença salarial em relação aos homens exercendo o mesmo cargo" (ENTREVISTA, junho,2017).

A jovem consultora que é mãe de um menino acredita que é possível empreender e conciliar seu trabalho à maternidade, para ela basta ter um planejamento rígido de tempo, para sincronizar todas as atividades, com organização e produtividade, a fim de aproveitar todos os momentos tanto na empresa como com a família. "Quando a gente é mãe, a gente desenvolve inclusive algumas habilidades muito interessantes, como a intuição, a sensibilidade, a resiliência, a tolerância", afirma ela (ENTREVISTA, junho, 2017).

Apesar dos contratempos, a jovem empreendedora ama o que faz e aconselha que para se aventurar no mundo empreendedor, a pessoa deve gostar do que faz porque vai exigir muita dedicação e sacrifício e ainda exemplifica "não adianta uma pessoa que não gosta de cozinhar, abrir um restaurante, será que ela vai pensar em inovação? Em pratos novos? Ela vai aguentar o ritmo do restaurante? Então, o ideal é que você goste que você se identifique".

Afinal, a trajetória vivida e marcada pelos traços pertinentes ao empreendedorismo presentes desde a infância, e prosseguindo pela vida inicial da empreendedora, culmina com contribuições e aprendizados. O que corrobora com o que foi observado na revisão teórica: a relação existente entre o desenvolvimento do espírito empreendedor e o ambiente vivencial da família.

\section{CONSIDERAÇÕES FINAIS}

A pesquisa discutiu a influência que a história de vida de uma empreendedora causa na formação de uma empresa em consultoria empresarial. Nesse estudo foi observado que a empresária possui algumas características balizadoras de uma empreendedora, tais como: busca de oportunidade e iniciativa, persistência, exigência de qualidade e eficiência, busca de informações, planejamento e monitoramento sistemático e persuasão e rede de contatos. Mas, também foi visto que elas são construídas e potencializadas desde a infância e a vivência que o indivíduo possui no decorrer de sua trajetória de vida.

Revisitando e confirmando a abordagem de McClelland (1972), que as primeiras experiências agem como um papel significativo nas futuras situações, os resultados pertinentes na entrevista e ao longo da pesquisa criam um ponto de congruência entre a teoria e a prática.

A pesquisa salientou características de uma empreendedora com criatividade, marcada pela competência de estabelecer e atingir objetivos, possuindo referências conceituadas para captar oportunidades de negócios, que busca aprendizagem continuada, utiliza o processo de tomada de decisão com risco moderado, visa à inovação, autoconfiante, com grande poder de liderança, possui planejamento e monitoramento sistemático, é comprometida, preza pela 
A Influência da História De Vida De Uma Empreendedora Na Formação De Uma Consultoria Empresarial.

qualidade e eficiência, e por fim, detém persuasão e redes de contatos.

Diante das características postas, viu-se que o perfil empreendedor tem influência na vida de uma empresária de sucesso, sendo que esse conjunto de características faz jus ao ambiente que ele atua e sofre influência.

O presente estudo deixa margem para futuros trabalhos, acerca do comportamento empreendedor, que contemplem o olhar para regiões e pessoas com experiências diferentes e possa haver um comparativo entre a realidade das diferentes regiões e diferentes ambientes, tendo em mente que na análise psicossocial os empreendedores podem sofrer influências do ambiente e que está inserido. Propõe-se então, como sugestão de pesquisa, o comparativo entre as características intrínsecas ao empreendedor em diferentes regiões e situações.

\section{REFERÊNCIAS}

ADMINISTRADORES. Pesquisa revela perfil das empresas de consultoria brasileiras. 2016. Disponível em: $<$ http://www.administradores.com.br/noticias/negocios/pesquisa-revela-o-perfilas-empresas- de-consultoria-brasileiras/114291/>. Acesso em: 20 jul. 2017.

ALVES, J. C.; DIAS, N. T.; MONSROES, G. L. Consultoria empresarial como ferramenta estratégica de desenvolvimento em pequenas empresas. In: XII SEGET - Simpósio de Excelência em Gestão e Tecnologia: Otimização de recursos e desenvolvimento. 2015. Disponível em: <https://www.aedb.br/seget/arquivos/artigos 15/32022351.pdf>. Acesso em: 08 out. 2017.

BARON, R. A.; SHANE, S. A. Empreendedorismo: uma visão do processo. Tradução: All Tasks. São Paulo: Cengage Learning, 2007.

BUENO, A. M.; LEITE, M. L. G.; PILATTI, L. A. Empreendedorismo e comportamento empreendedor: como transformar gestores em profissionais empreendedores. Brasil, 03 a 05 de nov de 2004. ENCONTRO NAC.DE ENG.DE PRODUÇAO - Florianópolis, SC, Brasil,03 a 05 de nov. de 2004. Disponível em

〈http://pg.utfpr.edu.br/dirppg/ppgep/ebook/2004/14.pdf〉. Acesso em: 25 set. 2017. CHIAVENATO, I. Empreendedorismo: dando asas ao espírito empreendedor. 4 ed. São Paulo: Saraiva, 2014.

CONCEIÇÃO, G. J. Consultoria empresarial como ferramenta de gestão financeira para pequenas empresas: um estudo de caso na FKS moda center da cidade de conceição do Almeida-BA. Revista Formadores: Vivências e Estudos, v.8 n.2, p. 25-36, 2015.

DOLABELA, F. O ensino de empreendedorismo: panorama brasileiro. In: SEMINÁRIO A UNIVERSIDADE FORMANDO EMPREENDEDORES, maio 1999b, Brasília. Brasília:

CNI, 1999b. Apostila.

Oficina do empreendedor. São Paulo: Cultura, 1999a.

DONADONE, J. C.; SILVEIRA, Frederico Zenorini da Silveira; RALIO, Vanise Rafaela Zivieri. Consultoria para pequenas e médias empresas: as formas de atuação e configuração no espaço de consultoria brasileiro. Gestão da Produção: São Carlos, v. 19, n. 1, p. 151-171, 2012

DORNELAS, J. C. A. Empreendedorismo: transformando idéias em negócios. $1^{a}$ ed. São Paulo: Campus, 2001

Empreendedorismo: transformando idéias em negócios. $3^{\text {a }}$ ed. Revista e atualizada. São Paulo:Campus, 2008.

FILION, L. J. Empreendedorismo: Empreendedores e proprietários-gerentes de pequenos negócios.Revista de Administração, São Paulo, v. 34, n. 2, p. 5-28, abr./jun. 1999.

O planejamento do seu sistema de aprendizagem empresarial: identifique uma visão e 
A Influência da História De Vida De Uma Empreendedora Na Formação De Uma Consultoria Empresarial.

avalie o seu sistema de relações. Revista de Administração de Empresas, São Paulo, v. 31, n. 3, p. 63-71, jul./set. 1991.

GEM - GLOBAL ENTREPRENEURSHIP MONITOR. Empreendedorismo no Brasil - 2015, Curitiba: IBQP, 2015. Disponível em:<https://www.sebrae.com.br/sites/PortalSebrae/bis/pesquisagem-revela-taxa-de- empreendedorismo-no pais, eb3913c334085510vgnVCM1000004c002110aRCRD>. Acesso em:16 jul. de 2017.

GEM - GLOBAL ENTREPRENEURSHIP MONITOR. 2016. Disponível em: $<$ http://www.bibliotecas.sebrae.com.br/chronus/ARQUIVOS_CHRONUS/bds/bds.nsf/b8e b2dfb4fca9e5c31bd5a05f89374a7/\$File/7577.pdf>. Acessado em: 01 de agosto de 2017.

GEM - GLOBAL ENTREPRENEURSHIP MONITOR. Empreendedorismo no Brasil - 2017, Curitiba:IBQP,2017.Disponível em:<http://www.sebrae.com.br/Sebrae/Portal\%20Sebrae/Anexos/GEM\%20Nacional\%20\%20web.pdf $>$. Acesso em: 01 ago. 2017.

GUEIROS, M. M. B. Empreendedores exitosos: família, trajetória, desafios e oportunidades. In: CONGRESSO LUSO-AFRO-BRASILEIRO DE CIÊNCIAS SOCIAIS, 8, 2004, Coimbra. Artigo. Coimbra: UFBA, 2004. Disponível em: 〈www.ces.uc.pt/LAB2004〉. Acesso em: 29 out. 2017.

GREATTI, L; SENHORINI, V. M. Empreendedorismo - Uma visão comportamentalista. In: GREATTI, Lígia. Perfis Empreendedores: Análise comparativa das trajetórias de sucesso e do fracasso empresarial no Município de Maringá. Maringá, PR, 2003, 167 p. Dissertação (Mestrado em Administração) - Universidade Estadual de Maringá e Universidade Estadual de Londrina, consorciadas, Maringá, 2003. Disponível em:

$<$ http://www.google.com.br/url?sa=t\&rct=j\&q=\&esrc=s\&source=web\&cd=1\&ved=0CCwQFj AA\&url=http $\% 3 \mathrm{~A} \% 2 \mathrm{~F} \% 2 \mathrm{Fperiodicos}$.unifacef.com.br\%2Findex.php $\% 2 \mathrm{Ffacefpesquisa} \% 2 \mathrm{Fa}$ rticle\%2Fdownload\%2F45\%2F111\&ei=rVOtUNbuPKnD0AGq64DIBQ\&usg=AFQjCNEb4T X9SEzCGvpS64oFTklxUCbBeg>. Acessado em: 15 nov. 2017.

JACINTHO, P. R. B. Consultoria empresarial: procedimentos para aplicação em micro e pequenas empresas. Dissertação (Mestrado em Engenharia de Produção) - Programa de PósGraduação em Engenharia de Produção, UFSC, Florianópolis, 2004.

LAKATOS, E. M.; MARCONI, M. A. Fundamentos da metodologia científica.6 ed. São Paulo: Atlas, 2010.

KURB, M. Consultoria: um guia para a profissão. Rio de Janeiro: Guanabara, 1986. LOPES, Karen Patrícia de Paula. Avaliação do impacto provocado pelo empretec na vida empresarial de empresários de Rio Branco-Acre. 2007. 66f. Monografia (Graduação em Economia) Universidade Federal do Acre, Rio Branco, 2007.

MACHADO, H.P.V. Tendências do comportamento gerencial da mulher empreendedora. Anais do XXIII EnANPAD - Associação Nacional de Pós-Graduação e Pesquisa em Administração. v. 23. Foz do Iguaçu, 1999.

MATIAS, M. R. D. Empreendedorismo feminino: análise das características empreendedoras femininas no município de Ingá-PB. Trabalho de Conclusão de Curso. (Graduação em Administração). Universidade Estadual da Paraíba. Campina Grande, 2016.

MCCLELLAND, D. C. A sociedade competitiva: realização e progresso social. Rio de Janeiro: Expressão e Cultura, 1972.

MINAYO, M. C. S.O desafio do conhecimento: pesquisa qualitativa em saúde. 10 ed. São Paulo: Hucitec, 2007.

OLIVEIRA, D. P. R. Manual de consultoria empresarial: conceitos, metodologia e práticas. São Paulo: Atlas, 2001.

PARREIRA, F. E. Consultoria, consultores e clientes. São Paulo: Érica, 1997. 
A Influência da História De Vida De Uma Empreendedora Na Formação De Uma Consultoria Empresarial.

PNAD. Pesquisa Nacional por Amostra de Domicílios: síntese de indicadores 2014 / IBGE, Coordenação de Trabalho e Rendimento. - Rio de Janeiro: IBGE, 2015. 102 p.

SCHUHLY, Gunther Franz. Motivação e desenvolvimento. São Paulo: Loyola, 1995. Disponível em: <http://books.google.com.br/books?id=KM5fpzZXJaoC\&pg=PA29\&lpg=PA29\&dq=McClell and+-+infancia\&source $=$ bl \&ots $=8$ co-nTlym6\&sig $=$ ZFz7guDH tB- $\quad$ u1 VsTag1EDdfsQ\&hl=ptBR\&sa=X\&ei=z77ZUYy2IvCw0QHetYHIAg\&ved=0CEEQ6AEwAg\#v=onepage\&q=McCl elland\%20-\%20infancia\&f=false >. Acesso em: 20 de outubro de 2017.

SCHEIN, E. H. Consultoria de procedimentos: seu papel no desenvolvimento organizacional. São Paulo: Edgard Blücher, 1972.

SOUZA, E. C. L.; FRACASSO, E. M. Caso de Ensino - Casa Flor. Um caso de empreendedorismo em pequeno negócio. Revista de Administração e Inovação, São Paulo, v. 05, n. 03, p. 141-150, 2008. Disponível em:

<http://www.revistarai.org/rai/article/view/210 >. Acessado em: 16 out. 2017.

TAKAHASHI, A. R. W.;ZAMPIER, M. A.; TEIXEIRA,R. M.; GRZYBOVSKI, D. Intraempreendedorismo feminino e desenvolvimento de competências empreendedoras: um estudo de caso com professoras de programas de mestrado e doutorado em administração de Curitiba-PR. Revista Economia \& Gestão - v. 11, n. 25, jan./abril. 2011. ISSN 1984-6606.

TEIXEIRA, R. M. et al. Empreendedorismo jovem e a influência da família: a história de vida de uma empreendedora de sucesso. Revista de Gestão, São Paulo, 2010. Disponível em: <https://www.revistas.usp.br/rege/article/view/36722/39443> . Acesso em: 12 set. 2017. TRIVIÑOS, A.N.S. Introduçãoà pesquisa em ciências sociais: a pesquisa qualitativa em educação. São Paulo: Atlas, 1997. 
A Influência da História De Vida De Uma Empreendedora Na Formação De Uma Consultoria Empresarial.

\section{APÊNDICE A - ROTEIRO DA ENTREVISTA}

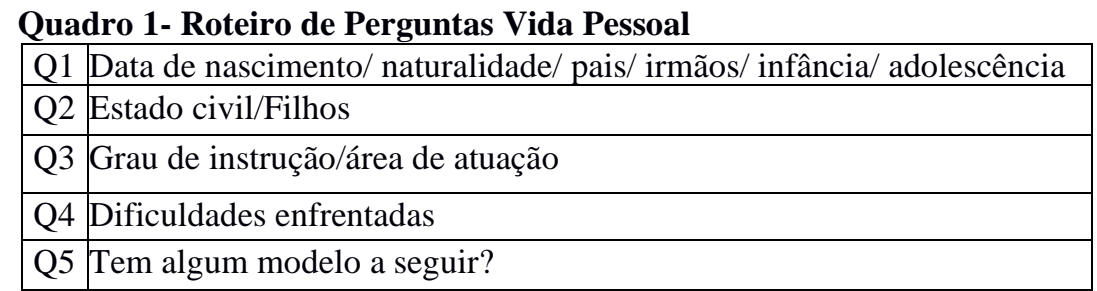

Fonte: Autores (2018)

Quadro 2- Roteiro de Perguntas Perfil Profissional

\begin{tabular}{|c|c|}
\hline Q1 & Relatar um pouco da vida profissional(experiências profissionais) \\
\hline Q2 & Que experiência você tinha no ramo? O que pode se destacar do seu comportamento empreendedor \\
\hline Q3 & Qual o ponto de gatilho que motivou a ideia de abrir uma empresa de consultoria? \\
\hline Q4 & Tiveram sócios? Onde buscou investimento para o negócio? \\
\hline Q5 & Teve apoio da família? Algum familiar já era empreendedor ou trabalha no ramo? \\
\hline Q6 & Você tinha algum conhecimento sobre elaboração de planejamento estratégico de negócios? \\
\hline Q7 & Qual objetivo você tinha pretensão de atingir com consultoria?(Pessoal, profissional ou financeiro) \\
\hline Q8 & Quais eram ás suas análises financeiras e de mercado percebidas ao abrir a consultoria? \\
\hline Q9 & Como você se posiciona frente aos concorrentes? Qual o seu diferencial competitivo? \\
\hline Q10 & Como você avalia a gestão utilizada naquela época e como você avalia a gestão atual? \\
\hline Q11 & Como você seleciona as pessoas para trabalhar com você? \\
\hline Q12 & Estratégias de crescimento? \\
\hline Q13 & O que é sucesso para você? \\
\hline Q14 & Como lidar com o fracasso em sua opinião? Como reconhecer uma oportunidade? \\
\hline Q15 & Pontos fracos e pontos fortes da sua empresa? \\
\hline Q16 & Relação entre os stakeholders? \\
\hline Q17 & Qual sugestão você daria para alguém que está pensando em iniciar um negócio? \\
\hline Q18 & O que levou você a escolher fazer publicidade já que sua mãe queria que você fizesse direito ou medicina? \\
\hline Q19 & $\begin{array}{l}\text { O que motivou você a abrir uma empresa de consultoria aqui em Juazeiro e como você conseguiu se } \\
\text { colocar no mercado de trabalho do Cariri? }\end{array}$ \\
\hline Q20 & $\begin{array}{l}\text { Como você sabe a ascensão feminina está cada vez mais gritante no mercado de trabalho, gostaria que } \\
\text { você fizesse uma análise, como é que você ver essa ascensão feminina tanto no mercado global e } \\
\text { especialmente aqui no Cariri? }\end{array}$ \\
\hline Q21 & $\begin{array}{l}\text { Você já foi professora de universidade e de faculdade, gostaria de saber se você pretende a voltar a } \\
\text { lecionar? }\end{array}$ \\
\hline Q22 & $\begin{array}{l}\text { No seu currículo Lattes está dizendo que você ainda está concluindo o Doutorado, não sei se está } \\
\text { desatualizado, eu gostaria de saber qual foi o período que você terminou seu doutorado? }\end{array}$ \\
\hline Q23 & Você abriu um canal no Youtube, qual foi a finalidade desse canal? \\
\hline Q24 & Explique sobre o símbolo da peça de xadrez que tem na marca da sua empresa, a Rainha? \\
\hline Q25 & Qual foi a primeira multinacional que você trabalhou e qual era a sua idade na época? \\
\hline
\end{tabular}


A Influência da História De Vida De Uma Empreendedora Na Formação De Uma Consultoria Empresarial.

Q26 Você é mãe do Pedro, depois da maternidade, você ver a mulher empreendedora que tem filhos de qual maneira, como ela deve se comportar diante do mercado do Cariri principalmente?

Q27 Quantos livros você tem de sua autoria e quais os assuntos abordam

Q28 Você já fez capacitação no SEBRAE? 